City University of New York (CUNY)

CUNY Academic Works

Publications and Research

City College of New York

2017

\title{
Quantitative Analysis of Regenerative Energy in Electric Rail Traction Systems
}

Mahmoud Saleh

CUNY City College

Oindrilla Dutta

CUNY City College

Yusef Esa

CUNY City College

Ahmed Mohamed

CUNY City College

\section{How does access to this work benefit you? Let us know!}

More information about this work at: https://academicworks.cuny.edu/cc_pubs/636

Discover additional works at: https://academicworks.cuny.edu

This work is made publicly available by the City University of New York (CUNY).

Contact: AcademicWorks@cuny.edu 


\title{
Quantitative Analysis of Regenerative Energy in Electric Rail Traction Systems
}

\author{
Mahmoud Saleh, Student Member, IEEE, Oindrilla Dutta, Student Member, IEEE, Yusef Esa, \\ Member, IEEE, and Ahmed Mohamed, Senior Member, IEEE
}

\begin{abstract}
This paper aims at determining the influential factors affecting regenerative braking energy in DC rail transit systems. This has been achieved by quantitatively evaluating the dependence of regenerative energy on various parameters, such as vehicle dynamics, train scheduling, ground inclination and efficiency of the electrical devices. The recuperated power and energy have been presented by a mathematical model, comprising of a set of empirical forms, which allows for thorough analysis. A detailed simulation model of a typical DC-traction system has been developed to validate the developed empirical forms. The results verified the validity of the proposed mathematical model, and demonstrated the significance of the examined parameters on the regenerative power and energy of a train during a complete cycle. Knowledge of the parameters impacting the magnitude of regenerative energy should maximize the potential of harnessing regenerative energy.
\end{abstract}

Index Terms-DC traction systems, electrical system, mathematical modeling, quantitative analysis, regenerative energy, reversible substations, Simulink model, train, vehicle dynamics, wayside energy storage.

\section{NOMENCLATURE}

\section{A. Vehicle dynamics}

\begin{tabular}{ll}
$A$ & Projected frontal area of the vehicle/train. \\
$B$ & Vehicle losses. \\
$C_{w}$ & Drag coefficient. \\
$F_{t r a c}$ & Tractive force. \\
$F_{R}$ & Resistive forces. \\
$F_{r r}$ & Rolling resistive force. \\
$F_{a r}$ & Aerodynamics drag force. \\
$F_{g r}$ & Gradient force due to slope/inclination of the rail. \\
$g$ & Acceleration due to gravity $\left(9.81 \mathrm{~m} / \mathrm{s}^{2}\right)$. \\
$M$ & Effective mass of the train. \\
$n_{c}$ & Numbers of cars of the train. \\
$r$ & Radius of the train's wheel. \\
$T_{a}, \omega_{a}$ & Torque and angular velocity at each axle of the train's car, \\
$T_{G}, \omega_{G}$ & respectively. \\
\multicolumn{3}{c}{ Torque and angular velocity upstream the gearbox, } \\
$f_{r}$ & respectively. \\
$v$ & Rolling resistance coefficient. \\
$\alpha$ & Imposed train velocity. \\
$\rho$ & Inclination angle. \\
$\gamma_{G}$ & Air density. \\
$\eta_{G}$ & Gearbox ratio. \\
$B$. & Gearbox efficiency. \\
$E_{r e g e n}$ & Regenerative energy \\
$E_{T}$ & Total energy during a train complete cycle. \\
$K_{s p}$ & Rate of the train speed during deceleration. \\
$P_{e l e c}$ & Electrical power of the train during a cycle.
\end{tabular}

This work was supported by Consolidated Edison, New York, NY. Mahmoud Saleh, Oindrilla Dutta, Yusef Esa and Ahmed Mohamed are with the Smart Grid Laboratory, Department of Electrical Engineering, CUNY City College, New York, NY 10031.

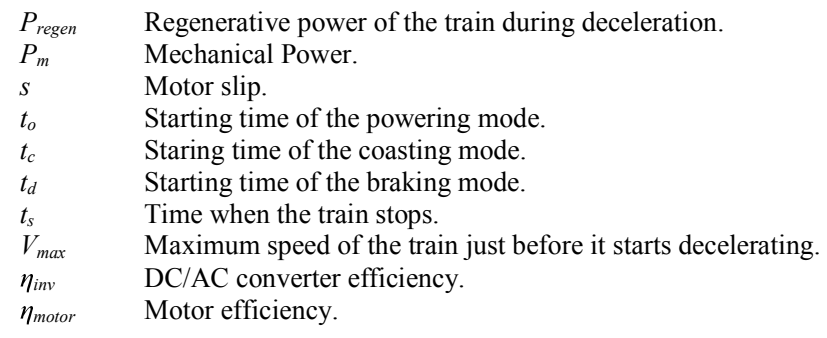

\section{INTRODUCTION}

TRIGGERED by the global initiatives to reduce energy consumption and carbon footprints, harnessing regenerative energy has been gaining an ever-increasing momentum. The DC rail traction system is a consumer of a substantial amount of electrical energy annually. Therefore, trains with regenerative braking capability are becoming increasingly popular, since they have the potential to reduce annual energy expenditure. A multitude of solutions, applicable to the DC-rail transit systems of various countries, have been advocated in different studies [1]-[3]. One such research shows a multi-train analysis to shed light on the percentage of energy regenerated for different headways for the Beijing Yizhuang subway system [4]. Another methodology, where the train braking speed trajectory has been optimized by Bellman-Ford algorithm to achieve improvement in the percentage of regenerated energy, has been presented in $[5]$.

The components of the electrical system, including the converters and energy storage technologies, are being improved upon, which facilitates the process of recuperating energy. A full-scale 1.5 MW converter, stacked in series, was installed in a DC traction substation to function as a regenerative converter and active power filter [6]. The modeling and control of electric drives, typically for regenerative energy, using ultra-capacitor as the energy storage system have been discussed in [7].

The dynamics of train movement, for the purpose of multitrain simulation, have been thoroughly derived for evaluation of energy recovery [8], [9]. However, to the best of our knowledge, no analysis has highlighted the influence of system parameters on the recovered energy. In this paper, the effect of DC traction system variables, on the magnitude of regenerative braking energy have been extensively discussed. This analysis has been established with the help of mathematical modeling of power and energy, during various modes of train movement. A simulation model of a single train, moving between three passenger stations, has also been developed to verify the outcome of the mathematical model. 
The paper is arranged as follows: Section III provides a detailed derivation of the mathematical modeling for both vehicle dynamics and regenerated energy. Section IV gives an overview of the simulation model, followed by Section V, which discusses the results obtained from both the previous sections. Section VI concludes the paper with a discussion of the applications and future work relevant to this paper.

\section{MATHEMATICAL MODELING}

In this section, analysis of the impact of vehicle dynamics parameters, DC/AC converter and motor efficiency on power and regenerative energy during train braking has been conducted. The magnitude of regenerative braking energy is affected by various parameters. In order to perform quantitative analysis, a mathematical model for vehicle dynamics has been adopted from [8], [9]. This model has then been modified to obtain the equations governing the power and regenerative energy during the braking mode of DC rail systems.

\section{A. Vehicle Dynamics}

The main variables associated with the train motion are position, velocity and acceleration. These variables, along with the forces affecting the motion of the train as shown in Fig. 1, are related through Newton's second law of motion [10], [11], which can be used to describe the train's motion as follows:

$$
\begin{aligned}
& F_{\text {Trac }}-\sum F_{R}=M \frac{d v}{d t} \\
& F_{R}=F_{r r}+F_{a r}+F_{g r} \\
& F_{r r}=f_{r} M g \cos \alpha \\
& F_{a r}=\frac{1}{2} C_{w} A \rho v^{2} \\
& F_{g r}=M g \sin \alpha
\end{aligned}
$$

Using (1-a) to (1-e):

$F_{\text {Trac }}=f_{r} M g \cos \alpha+\frac{1}{2} C_{w} A \rho v^{2}+M g \sin \alpha+M \frac{d v}{d t}$

Presumably, the torque will be equally distributed among the train cars, and considering the fact that each car has four axles; the torque and speed for each axle can be calculated as in (3) and (4):

$$
\begin{aligned}
& T_{a}=\frac{F_{\text {Trac }} r}{4 n_{c}} \\
& \omega_{w}=\frac{v}{r}
\end{aligned}
$$

In order to assure high torque at the wheels, a gearbox is utilized to increase the torque from the induction motor shaft.

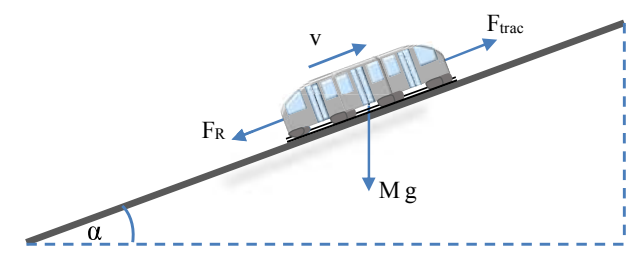

Fig. 1. Forces affecting train motion.
Therefore, to determine the torque and speed of induction motor shaft, (5) and (6) can be used:

$T_{G}=\frac{T_{a}}{\gamma_{G}}+\frac{B}{\gamma_{G}}$
$\omega_{G}=\omega_{w} \gamma_{G}$

Where the sign depends on whether the train is in motoring or braking mode. The vehicle losses can be represented by the following equation [9]:

$B=T_{a}\left(1-\eta_{G}\right)$

\section{B. Regenerative Energy}

Regenerative braking of a rail transit system takes place when the kinetic energy of the motor is returned back to the supply. This energy can be harnessed using various storage techniques. However, for an effective transfer of energy to take place, it is essential to recognize the factors governing the magnitude of regenerative energy. Such factors are identifiable from Fig. 2, which shows the power flow from the load (i.e. the train) to the storage system.

The equations pertaining to Fig. 2 have been developed in the following discussion. It is worth mentioning that regenerative energy has been calculated up to the point of connection of the inverter and chopper.

The mechanical power can be represented as,

$P_{m}=T_{G} \omega_{G}$

Since there are 4 axles per car,

$P_{\text {regen }}=4 n_{c} \eta_{\text {inv }} \eta_{\text {motor }} P_{m}$

Substituting (1-a), (1-b), (3), (4), (5), and (6) in (9), the following is obtained:

$P_{\text {regen }}=\eta_{\text {inv }} \eta_{\text {motor }}\left[\left(F_{r r}+F_{a r}+F_{g r}+M \frac{d v}{d t}\right)-\frac{4 n_{c} B}{r}\right] v$

As $F_{r r}$ and $F_{a r}$ do not vary with time,

$K_{1}=F_{r r}+F_{g r}$

$K_{a e}=\frac{1}{2} C_{w} A \rho$

Where $K_{1}$ and $K_{a e}$ are constants. Therefore,

$P_{\text {regen }}=\eta_{\text {inv }} \eta_{\text {motor }}\left[\left(K_{1}+K_{a e} v^{2}+M \frac{d v}{d t}\right)-\frac{4 n_{c} B}{r}\right] v$

The term $\frac{4 \mathrm{n}_{\mathrm{c}} B}{\mathrm{r}}$ from (17) has been evaluated as,

$\frac{4 n_{c} B}{r}=F_{\text {Trac }}\left(1-\eta_{G}\right)=\left(K_{1}+K_{a e} v^{2}+M \frac{d v}{d t}\right)\left(1-\eta_{G}\right)$

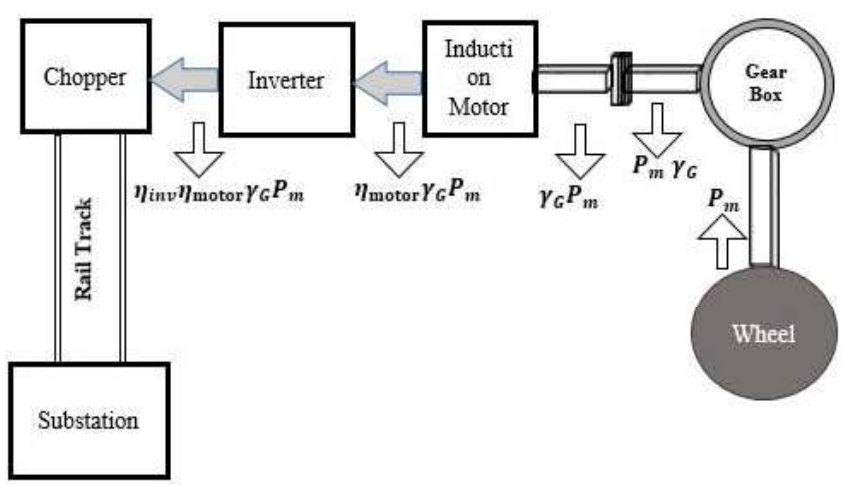

Fig. 2. Power flow diagram for the train in DC-traction system. 
Let,

$$
C_{G}=\left(1-\eta_{G}\right)
$$

This leads to,

$P_{\text {regen }}=\eta_{\text {inv }} \eta_{\text {motor }}\left(1-C_{G}\right)\left(K_{1} v+K_{a e} v^{3}+M v \frac{d v}{d t}\right)$

During braking and powering, in most practical cases, deceleration and acceleration are constant, while during coasting, the train speed is nearly constant [12], [13]. Hence, acceleration, deceleration, and speed could be represented as follows:

$$
\begin{aligned}
& a=\frac{V_{\max }}{t_{c}-t_{o}} \\
& d=\frac{V_{\max }}{t_{d}-t_{s}} \\
& V= \begin{cases}a\left(t-t_{o}\right) & t_{o}<t \leq t_{c} \\
V_{\max } & t_{c}<t \leq t_{d} \\
d\left(t-t_{s}\right) & t_{d}<t \leq t_{s}\end{cases}
\end{aligned}
$$

Therefore, the regenerative energy can be given by,

$$
E_{\text {regen }}=\int_{t_{d}}^{t_{s}} P_{\text {regen }} d t
$$

Substituting (16) and (19) in (20),

$$
E_{\text {regen }}=\eta_{\text {inv }} \eta_{\text {motor }}\left(1-C_{G}\right) \int_{t_{d}}^{t_{s}}\left(\mathrm{~K}_{1} v+\mathrm{K}_{a e} v^{3}+M v \frac{d v}{d t}\right) d t
$$

The expression of regenerative energy after integration is as follows:

$$
E_{\text {regen }}=-\eta_{\text {ivv }} \eta_{\text {motor }}\left(1-C_{G}\right)\left[\left(\frac{K_{1} a}{2}\left(t_{s}-t_{d}\right)^{2}\right)+\left(\frac{K_{a e} a^{3}}{4}\left(t_{s}-t_{d}\right)^{4}\right)+\left(\frac{M}{2} V_{\max }^{2}\right)\right]
$$

Similarly, during acceleration and coasting of the train, the power and energy can be developed in empirical forms. Therefore, $P_{\text {elec }}$ during train cycle can be formalized as in (23) and (24):

$$
P_{\text {elec }}(v)=\left\{\begin{array}{cc}
\eta_{\text {inv }} \eta_{\text {motor }}\left(1+C_{G}\right)\left(K_{1} v+K_{a e} v^{3}+M v \frac{d v}{d t}\right) & t_{o}<t \leq t_{c} \\
\eta_{\text {inv }} \eta_{\text {motor }}\left(1+C_{G}\right)\left(K_{1} v+K_{a e} V_{\text {max }}^{3}\right) & t_{c}<t \leq t_{d} \\
\eta_{\text {inv }} \eta_{\text {motor }}\left(1-C_{G}\right)\left(K_{1} v+K_{a e} v^{3}+M v \frac{d v}{d t}\right) & t_{d}<t \leq t_{s}
\end{array}\right.
$$

$P_{\text {elec }}(v)$ can be further simplified as a function of time as,

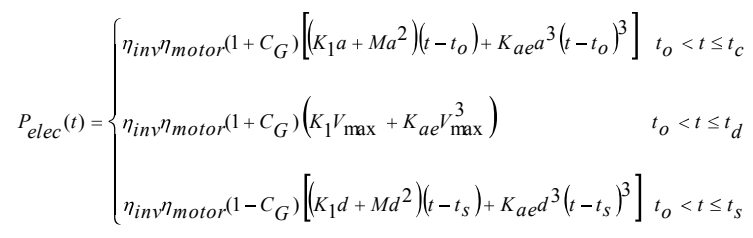

Similar to (20),

$$
E_{\text {elec }}=\int P_{\text {elec }}(t) d t
$$

Substituting $P_{\text {elec }}(t)$ in the above equation,

$$
E_{\text {elec }}(t)= \begin{cases}\eta_{i v v} \eta_{\text {motor }}\left(1+C_{G}\right)\left[\frac{\left(K_{1} a+M a^{2}\right)}{2}\left(t_{c}-t_{o}\right)^{2}+\frac{K_{a c} c^{3}}{4}\left(t_{c}-t_{o}\right)^{4}\right] & \text { Powering } \\ \eta_{\text {ivv }} \eta_{\text {motor }}\left(1+C_{G}\right)\left(K_{1} V_{\text {max }}+K_{a e} V_{\text {max }}^{3}\right)\left(t_{d}-t_{c}\right) & \text { Coasting } \\ \eta_{\text {iv }} \eta_{\text {motor }}\left(1-C_{G}\right)\left[\frac{\left(K_{1} d+M d^{2}\right)}{2}\left(t_{d}-t_{s}\right)^{2}+\frac{K_{a c} d^{3}}{4}\left(t_{d}-t_{s}\right)^{4}\right] & \text { Braking }\end{cases}
$$

(25) represents the energy of the train during a complete cycle, i.e. acceleration, constant speed, and deceleration. It can be observed that the $E_{\text {elec }}$ is affected by numerous variables such as, vehicle dynamics parameters, ground inclination angle $\alpha$, train schedule (i.e. powering, coasting, and braking time), electrical circuit components, mechanical components, and materials (i.e. friction coefficient of the rail). The impact of these parameters will be investigated in details Section V.

\section{SYSTEM UNDERSTUDY}

A DC traction system, powered by two substations, with a train moving between three passenger stations has been used as the main case study, as illustrated in Fig. 3. The corresponding electrical circuit diagram is shown in Fig. 4.

The topology of the substations is based on standard systems prevalent in several places, such as, New York City Transit. Each substation consists of two step-down star-delta and deltadelta transformers, each being connected to a capacitor, followed by two rectifier stations. The primary function of these

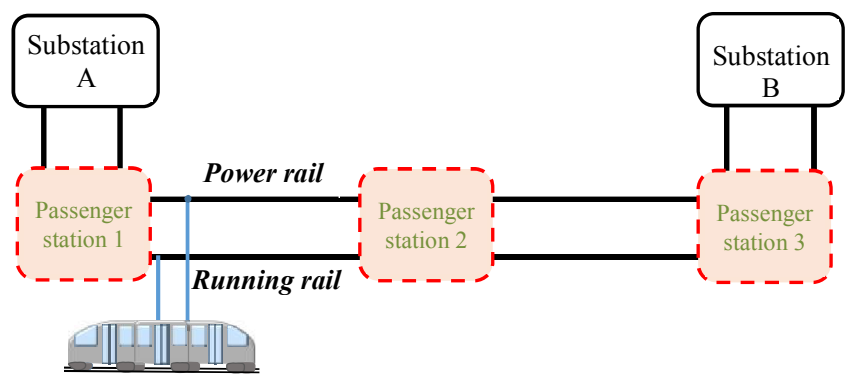

Fig. 3. Block diagram of the system understudy.

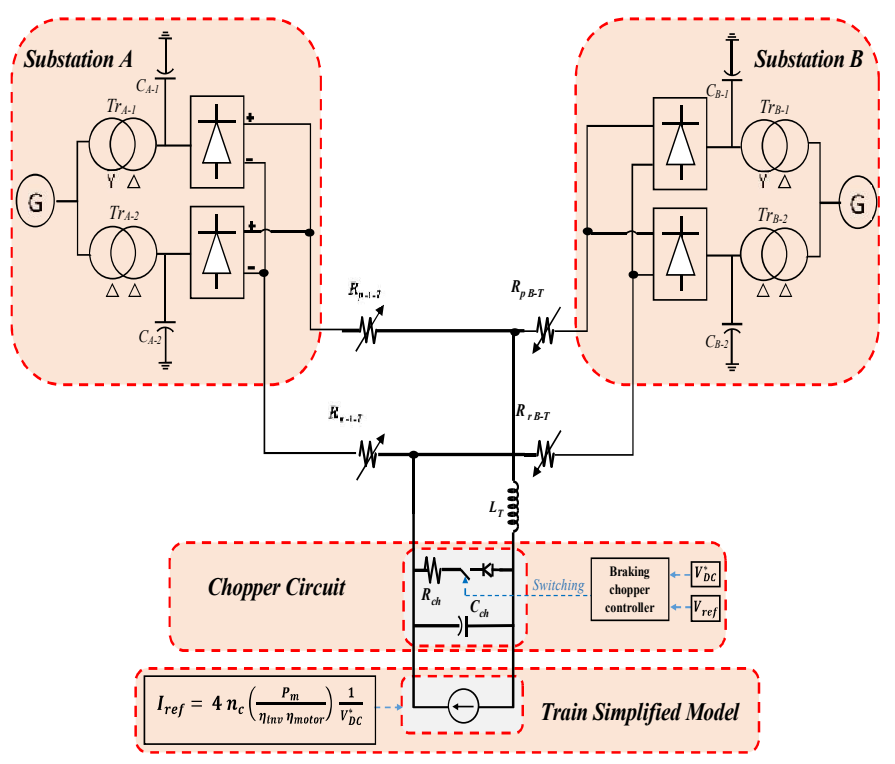

Fig. 4. Electrical circuit diagram of the system understudy. 
TABLE I

Electrical CIRCUIT PARAMETERS

\begin{tabular}{|c|c|c|}
\hline Unit & Parameter & Value \\
\hline \multirow{5}{*}{$\begin{array}{c}\text { Transformers: } \\
T r_{A-1}, \operatorname{Tr}_{B-1}, T r_{A-2}, \operatorname{Tr}_{B-2}\end{array}$} & Voltage level & $132 / 0.49 \mathrm{kV}$ \\
\hline & $\begin{array}{l}\text { Primary winding } \\
\text { resistance }\end{array}$ & $2.66 \Omega$ \\
\hline & $\begin{array}{c}\text { Primary winding } \\
\text { inductance }\end{array}$ & $6.6702 \mathrm{mH}$ \\
\hline & $\begin{array}{l}\text { Secondary winding } \\
\text { resistance }\end{array}$ & $0.0029 \Omega$ \\
\hline & $\begin{array}{l}\text { Secondary winding } \\
\text { inductance }\end{array}$ & $9.19^{*} 10^{-3} \mathrm{mH}$ \\
\hline $\begin{array}{c}\text { Capacitance between } \\
\text { rectifier station and } \\
\text { transformer }\end{array}$ & $\begin{array}{l}\mathrm{C}_{\mathrm{A}-1}, \mathrm{C}_{\mathrm{B}-2}, \\
\mathrm{C}_{\mathrm{A}-1}, \mathrm{C}_{\mathrm{B}-2}\end{array}$ & $1 \mathrm{mF}$ each \\
\hline \multirow[t]{2}{*}{ Rail } & $\begin{array}{c}R_{p A-T}, R_{p B-T}, \\
R_{r A-T}, R_{r B-T}\end{array}$ & $\begin{array}{l}13 \mathrm{~m} \Omega / \mathrm{km}, \\
35 \mathrm{~m} \Omega / \mathrm{km}\end{array}$ \\
\hline & Nominal voltage & $650 \mathrm{~V}$ \\
\hline DC filter & $\mathrm{L}_{\mathrm{T}}$ & $100 \mu \mathrm{H}$ \\
\hline \multirow{2}{*}{ Chopper } & $\mathrm{R}_{\mathrm{ch}}$ & $0.2 \Omega$ \\
\hline & $\mathrm{C}_{\mathrm{ch}}$ & $7500 \mu \mathrm{F}$ \\
\hline Motor & $\eta_{\text {motor }}$ & $90 \%$ \\
\hline DC/AC converter & $\eta_{\text {inv }}$ & $90 \%$ \\
\hline
\end{tabular}

capacitors is to subdue voltage transients on the AC side of the substations. In this paper, a train, consisting of ten cars, has been modelled by adopting "effect-cause" or "backward-looking" methodology [9]. This methodology uses the effect, which is the desired vehicle speed in this case, as the input to the simulation. The power and electromagnetic torque, which is required to attain this speed profile, is then calculated by the Simulink blocks. The train being powered by forty motors, four in each car, the simulation time for one complete run of the train is long ( $\sim 12$ hours). For the sake of simplicity, the detailed model of the train, consisting of forty induction motor drives, has been substituted by a current source using (26). Here, the mechanical power required by one axle is multiplied by the number of axles and is then expressed in terms of a current reference, as follows.

$I_{\text {ref }}=4 n_{c} \frac{T_{G} \omega_{c}}{\eta_{\text {inv }} \eta_{\text {motor }}} \frac{1}{V_{D C}^{*}}$

where, $V_{D C}^{*}$ is the measured value of the third rail voltage.

The chopper circuit, as shown in Fig. 4, has been modelled by employing a control system that activates a braking resistance based on a reference voltage $V_{\text {ref }}(650 \mathrm{~V}$ for the system under study). The chopper circuit is accompanied by a smoothing inductor $L_{T}$ which filters out the high ripples in the current. The motion of the train on the electrical rail has been designed by two pairs of variable resistors, each pair is for the power rail and the running rail. The resistors are function of the train position, i.e. as the train moves from one passenger station to the next, $R_{p A-T}$ and $R_{r_{A-T}}$ increase, while $R_{p B-T}$ and $R_{r B-T}$ decrease. The values used for the circuit model are shown in Table I [13]-[15] The train model can be found at [16].

\section{RESUlTS AND DISCUSSION}

The mathematical model, derived in Section III, has been validated with the help of results obtained from the Simulink model. The variation of $P_{\text {elec }}$ and $E_{\text {regen }}$ during a train cycle, with different values of vehicle dynamics parameters, inclination, train schedule, and electrical circuit components have been demonstrated and analyzed in this section.

Fig. 5 depicts the speed profile of the train implemented in the case studies alongside the values of the system parameters as shown in Table II. A comparative study between the simulation results and (24), for $P_{\text {elec, }}$ has been presented in Fig. 6 . It can be seen that, during the powering mode (i.e. $t_{o}$ to $t_{c}$ ), the electrical power drawn from the rail increases to maintain constant acceleration. During the coasting interval (i.e. between $t_{c}$ and $t_{d}$ ) $P_{\text {elec }}$ decreases, since it is only being consumed to overcome $F_{R}$ and maintain constant speed. The train starts braking at $t_{d}$ and reaches full stop at $t_{s}$, during which the train's motor functions as a generator. The train supplies $P_{\text {elec }}$ back to the third rail, during deceleration, where it can be stored in ESS, or dissipated in dynamic resistors. In order to check the accuracy of the mathematical model, the results have been compared with the output of the Simulink model. The profile for $P_{\text {elec }}$ obtained from the mathematical model conforms with that of the Simulink model for different combinations of $\alpha, M$, Vmax, and the deceleration time $\left(t_{d}-t_{s}\right)$. One such case is illustrated in Fig. 6, where $P_{\text {elec }}$ from (24) matches with $P_{\text {elec }}$ from the simulation.

Fig. 7 shows the impact of $\alpha$ on $P_{\text {elec }}$. It can be observed that a substantial difference in $P_{\text {elec }}$, drawn from the rail, occurs as $\alpha$ changes. It can be seen from Fig. 8 that one degree change in $\alpha$ results in 1.5 MW difference in the peak of $P_{\text {elec }}$ during acceleration and deceleration, which results in almost $15 \%$ variation in the consumed and regenerated energy, respectively. Moreover, when $\alpha$ is negative and the train is coasting, $F_{g r}$ is negative and it is the dominant force compared to $F_{a r}$ and $F_{r r}$ according to (27). This results in generating power because, during coasting $P_{\text {elec }}$ is constant and is being consumed by $F_{R}$ when $\alpha$ is zero (i.e. on a plain surface). However, if $\alpha$ is negative, the weight of the train and its inertia might be enough to maintain constant speed and generate $P_{\text {elec }}$. Furthermore, Fig. 7 demonstrates that as $\alpha$ increases in the positive direction (i.e. uphill), during acceleration, the consumption of $P_{\text {elec }}$ increases. Also during deceleration, the train might consume instead of generate power in order to bring the train to rest, depending on the value of $\alpha$. This is because more work is required to overcome $F_{g r}$, which increases as $\alpha$ increases, according to (28). In other words, the train has to overcome the difference in potential energy and maintain constant acceleration, speed or deceleration depending on the mode. Similarly, as $\alpha$ increases in the negative direction (i.e. downhill), $P_{\text {elec }}$ decreases during acceleration and it becomes negative, i.e. the train regenerates. Besides, during deceleration/acceleration, the train weight forces the train to accelerate. Hence, to maintain a constant deceleration/acceleration, the extra kinetic energy could be utilized to generate power. From the above discussion it can be

TABLE II

PARAMETERS INFLUENCING ENERGY PROFILE OF THE TRAIN

\begin{tabular}{c|c}
\hline \hline Parameter & Value \\
\hline$A$ & $9 \mathrm{~m}^{2}$ \\
\hline$C_{w}$ & 0.5 \\
\hline$M$ & $380 \mathrm{t}$ \\
\hline$\rho$ & $1.225 \mathrm{~kg} / \mathrm{m}^{3}$ \\
\hline$f_{r}$ & 0.002 \\
\hline$r$ & $0.4 \mathrm{~m}$ \\
\hline$g$ & $9.81 \mathrm{~m} / \mathrm{s}^{2}$ \\
\hline$\alpha$ & $0^{\circ}$ \\
\hline$\gamma_{G}$ & 6 \\
\hline$\eta_{G}, \eta_{\operatorname{motor}}, \eta_{\text {inv }}$ & $96 \%, 90 \%, 90 \%$ \\
\hline$V_{\max }$ & $18 \mathrm{~m} / \mathrm{s}, 41 \mathrm{mph}$ \\
\hline$t_{o}, t_{c}, t_{d}, t_{s}$ & $0.5,12.5,35.75,51 \mathrm{~s}$ \\
\hline \hline
\end{tabular}




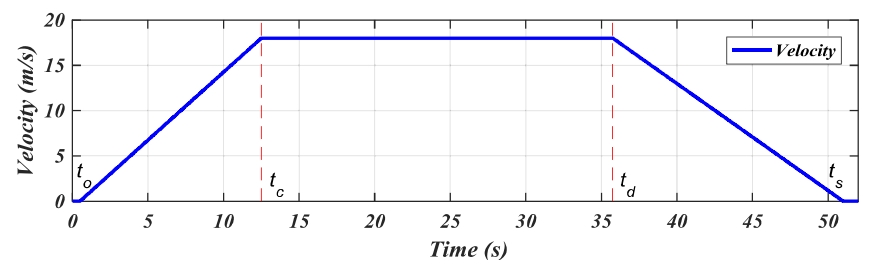

Fig. 5. Speed profile of the train.

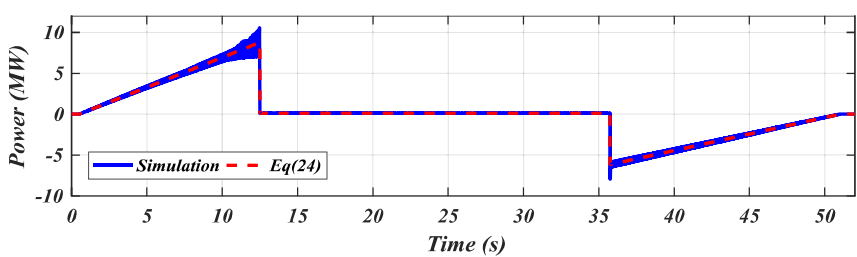

Fig. 6. $P_{\text {elec }}$ from (24) and the simulation.

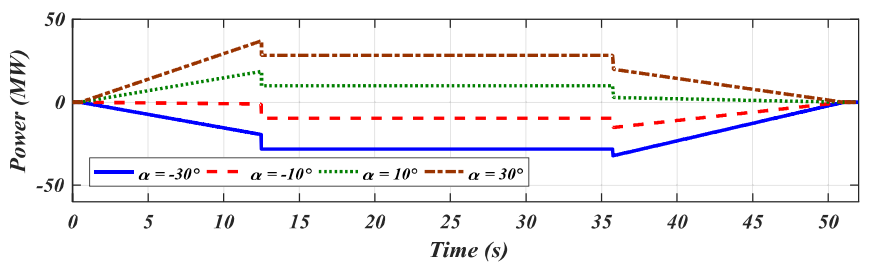

Fig. 7. $P_{\text {elec }}$ with different values of $\alpha$.

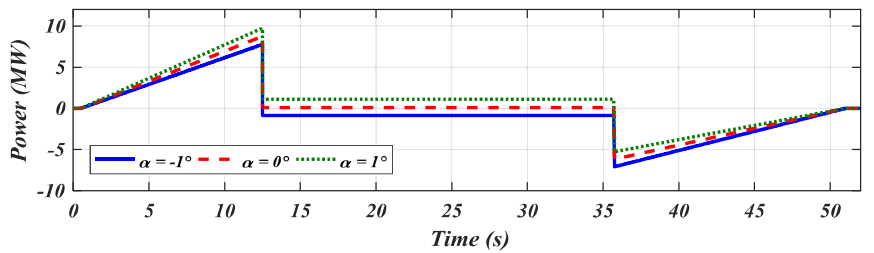

Fig. 8. $P_{\text {elec }}$ variation with $\pm 1^{\circ}$ of $\alpha$.

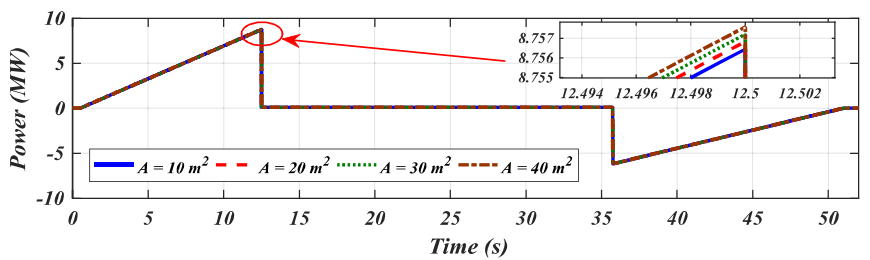

Fig. 9. $P_{\text {elec }}$ with different values of $A$.

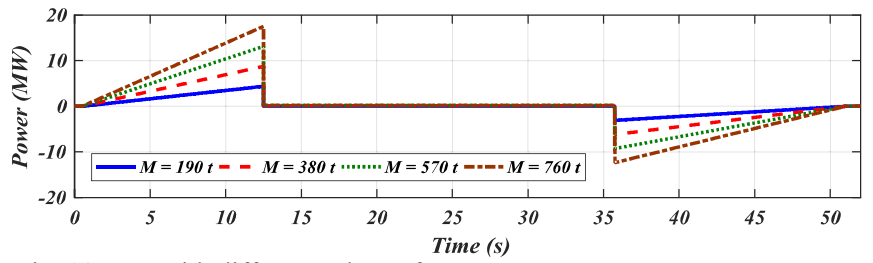

Fig. 10. $P_{\text {elec }}$ with different values of $M$.

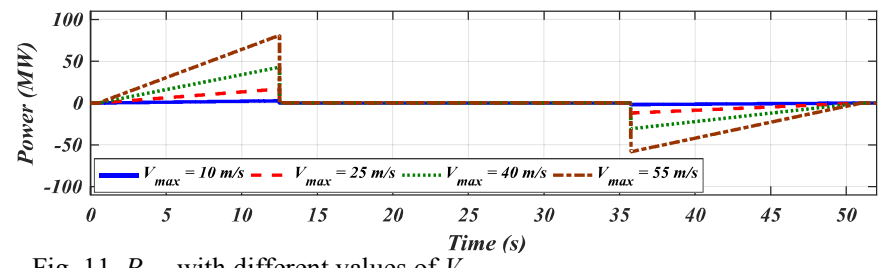

Fig. 11. $P_{\text {elec }}$ with different values of $V_{\max }$.

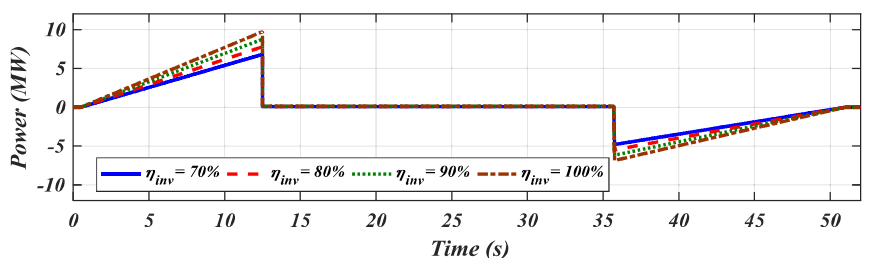

Fig. 12. $P_{\text {elec }}$ with different values of $\eta_{\text {inv }}$. inferred that $\alpha$ has a significant impact on $E_{\text {regen }}$ and consequently on the sizing of ESS to be installed in various passenger stations.

Fig. 9 demonstrates the impact of different values of $A$ on $P_{\text {elec }}$. It can be noticed that $A$ has almost negligible effect on $P_{\text {elec }}$ and consequently on $E_{\text {regen }}$. This is because $A$ is associated with the term that represents the aerodynamics drag force against train's motion, which is usually minimal. It impacts each cycle of the train, per day, which adds up over a year. However, this impact can still be neglected. For example, from Fig. 9, it is apparent that a difference of 10 to $40 \mathrm{~m}^{2}$ in the value of $A$ corresponds to around $0.001 \mathrm{MW}$ difference in $P_{\text {elec }}$. Assuming that the train completes an average of 50 cycles per day, this amount of energy difference is around $0.35 \mathrm{GJ} /$ year, which corresponds to a negligibly low value of $100 \mathrm{kWh} /$ year. Thus, $A$ is a design parameter which does not have significant impact on Eregen.

Fig. 10 demonstrates the variation of $P_{\text {elec }}$ with various values of $M$. It can be seen that as $M$ changes, $P_{\text {elec }}$ changes significantly. This is due to the fact that during acceleration/deceleration, a higher $M$ indicates a higher kinetic energy. However, $M$ does not have much effect on $P_{\text {elec }}$ during coasting as $d v / d t$ is zero. In this context (22) can be further simplified to:

$E_{\text {regen }}=\frac{\left(2 K_{1} V_{\max }+K_{a e} V_{\max }^{3}\right)}{4}\left(t_{d}-t_{s}\right)+\frac{M V_{\max }^{2}}{2}$

It can be observed from (27) that $F_{r r}$ and $F_{a r}$ do not have any significant effect on $P_{\text {elec }}$, even with higher masses. It is worth mentioning here that despite the fact that with higher $M$, more $E_{\text {regen }}$ could be captured, this will require more energy consumption during train acceleration, which will reduce the $E_{\text {regen }} \%$ during a full train cycle. However, since $E_{\text {regen }}$ is destined to be dissipated in dynamic resistors in form of heat, proper capturing is economically beneficial. In other words, this discussion does not suggest intentionally increasing the weight of the train to capture more regenerative energy, even though it does increase with mass.

Fig. 11 shows the change of the electric power with various $V_{\max }$ according to (28). It can be noticed that as $V_{\max }$ increases, the integration of $P_{\text {elec }}$ considerably increases; in other words, the energy increases. This can be explained by laws of mechanics, where kinetic energy as $\left(M V^{2} / 2\right)$ increases with the square of velocity. However, the distance traveled by the train between passenger stations has to be considered while planning to achieve higher $V_{\max }$. Moreover, safe speed limits have to be preserved. This implies that if the distance between stations is short, $V_{\max }$ cannot exceed certain limits to maintain safe operations. Furthermore, as the velocity is constant during coasting, from (27), the term associated with $d v / d t$ will tend to zero, and all the required $P_{\text {elec }}$ will be consumed only to overcome losses. If Fig. 10 is to be compared with Fig. 11, it can be noticed that variation of $V_{\max }$ has more impact on $P_{\text {elec }}$ than the variation of $M$. This is because, if $F_{R}$ is neglected, it can be seen from (28) that $P_{\text {elec }}$ varies linearly with $M$ and quadratically with $V_{\max }$. Therefore, if more $E_{\text {regen }}$ is desired to be acquired, the speed profile of the train has to be modified to reach higher $V_{\max }$ within safe practical limits. 
TABLE III

REgenerative Energy Percentage

\begin{tabular}{c|c}
\hline \hline Parameter & $E_{\text {regen }} / E_{T} \%$ \\
\hline$M=350$ to $760 \mathrm{t}$ & $\sim 46 \%$ \\
\hline$V_{\max }=10$ to $55 \mathrm{~m} / \mathrm{s}$ & $\sim 44.54$ to $47.33 \%$ \\
\hline$\eta_{\text {motor }}=90$ to $100 \%$ & $\sim 46 \%$ \\
\hline \hline$\eta_{\text {inv }}=90$ to $100 \%$ & $\sim 46 \%$ \\
\hline \hline
\end{tabular}
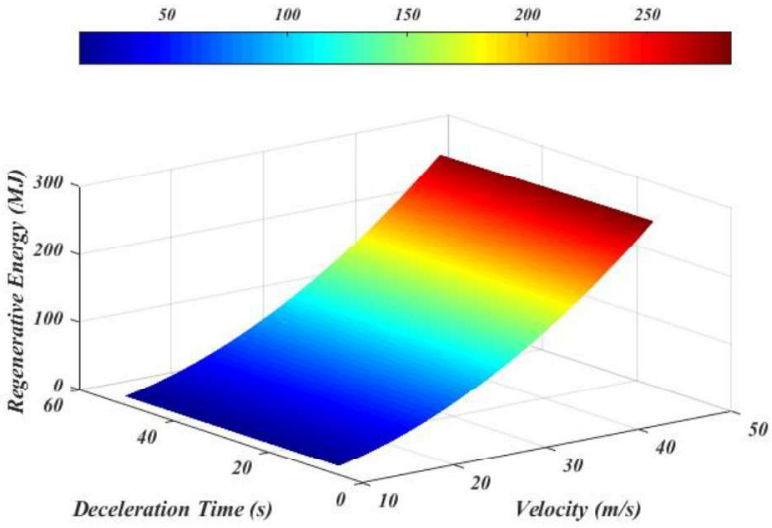

Fig. 13. Variation impact of deceleration time $\left(t_{d}-t_{s}\right)$ with $V_{\max }$ on $E_{\text {regen }}$.

Fig. 12 shows the impact of different $\eta_{i n v}$ on $P_{\text {elec }}$. It is a direct proportionality relation from (27), and the same applies to $\eta_{\text {motor }}$. However, they should be carefully considered during train

operation since they have significant impact on its $P_{\text {elec }}$ and energy. In this paper, both $\eta_{i n v}$ and $\eta_{\text {motor }}$ were considered to be constant during the train operation. The ideal efficiency of induction motors is $(1-s)$, which varies with the rotor speed. However, if the motor drive was properly designed to maintain maximum $\eta_{\text {motor }}$ during one complete cycle of the train, it is justified to assume that $\eta_{\text {motor }}$ is constant. Otherwise, it should be treated as a function of rotor speed. In other words, $\eta_{\text {motor }}$ is expected to be high or low based on $s$, which changes during the train cycle, unless the drive was designed to maintain constant $s$ by adjusting the frequency and consequently the synchronous speed of the rotating magnetic field. Similarly, $\eta_{i n v}$ varies with the switching losses, which might change during train operation (e.g. direct torque controlled inverter, which uses hysteresis band control). However, switching losses are minimal and the effect of its variation could be neglected. Thus $\eta_{i n v}$ could be considered constant. Note that if the train motor drive is not properly designed or its performance deteriorates due to aging, this may affect $E_{\text {regen }}$, and consequently ESS sizing. Thus, when considering sizing for ESS, performance of the drives (i.e. $\eta_{\text {motor }}$ and $\eta_{i n v}$ ) of the transit system should be investigated.

Fig. 13 shows the effect of change in deceleration time $\left(t_{d}-t_{s}\right)$ with $V_{\max }$ on $E_{\text {regen, }}$ according to (29). It is evident that, in order to maximize the regenerated energy, the train should be operated at highest possible speed, within safe practical limits,

right before the train starts decelerating. In (27), as $K_{l}$ and $K_{a e}$ are negligible compared to $M$, regenerative energy could be considered to vary as the square of $V_{\max }$, as shown in Fig. 13. Moreover, it can be observed that deceleration time has much less impact compared to $V_{\max }$ on regenerative energy, since it is associated with $F_{R}$ in (27), which are practically insignificant.
Thus, increasing $V_{\max }$ should be considered for an effective increase in harnessing regenerative energy while organizing train schedules.

Exploring the results in Figs. 10 through 12, $E_{\text {regen }}$ with respect to the energy during a complete cycle of the train for particular parameters values, can be seen in Table III. It is evident from Table III that inverter and motor efficiencies, as well as mass of the train has no effect on the percentage of energy recovered during braking. This is because, the electrical energy consumed during acceleration increases with mass. Thus, even though regenerative energy improves with heavier trains, the percentage harnessed over the entire cycle does not change. A careful observation of (25) shows that the efficiency of motor and inverter cancels out when $E_{\text {regen }}$ is expressed as a percentage of the total energy $\left(E_{\text {powering }}+E_{\text {coasting }}+E_{\text {regen }}\right)$. However, the controllable parameter, $V_{\max }$, improves the fraction of energy regenerated by almost $3 \%$ when it is increased by five times.

\section{CONCLUSION}

This paper analyzes the impact of vehicle dynamics, ground inclination, performance of the electrical components, and train schedule on the electrical power and energy during a complete cycle of a train in DC traction systems. A mathematical model was derived to better investigate the significance of the aforementioned parameters. Besides, the factors impacting regenerative energy were analyzed. The mathematical model was validated with a developed Simulink model that represents a train in a DC traction system.

Regenerative energy was analyzed to explore the influential weights of the system parameters. It was found that the amount of regenerative energy varies linearly with the mass of the train, efficiency of the electrical motor and inverter. However, it changes quadratically with the maximum velocity of the train at the instant when decelerating is initiated. This is due to the fact that kinetic energy that will be transformed to electrical energy varies with the square of the velocity. Moreover, the mathematical model revealed that the peak of the electrical power varies with the square of the maximum velocity. Furthermore, regenerative energy varies sinusoidally with the rail inclination. This impact of the weight of the train tends to be more prominent with the increase/decrease in the inclination angle of the track.

On the other hand, the impact of the frontal projected area, which is a design parameter of the train, is minimal. This is because it is related to the aerodynamic drag force, which is minor compared to the other forces impacting the train. Hence, harnessing regenerative energy in tunneled or open-air stations should not introduce a significant difference.

Therefore, if an effective increase in recuperating regenerative energy is to be pursued, above all, train scheduling has to be reorganized to increase $V_{\max }$. However, distance between stations has to be considered while planning to achieve higher velocities to maintain safe operations. It is worth mentioning that even though the train schedule includes decelerating time along with maximum velocity, the mathematical model shows that the force resistive to the train's motion, varies linearly with the decelerating time. In addition, since the resistive force effect on the train's motion is minimal; 
thus, impact of decelerating time on regenerative energy could be neglected.

The mathematical model also displayed that, sizing DC/AC converter in reversible substations or ESS within DC traction system, should consider the geographical location of the station. This is due to the fact that a $1^{\circ}$ inclination might cause around $15 \%$ change in energy regenerated. Moreover, the loading level of the station (i.e. number of people using this station) may be considered if very high accuracy is sought, e.g. a more crowded stations leads to higher mass, then sizing ESS or inverters may be different form less crowded stations.

Likewise, the efficiency of the electric drive (including motor and inverter) of the trains has to be considered. For example, if the trains running through a specific station have deteriorated electric drive due to aging, compared to modern trains with highly efficient electric drives, then magnitude of regenerative energy will vary.

Eventually, with the aid of the devised mathematical model, quantification of regenerative energy should be precise, and optimal sizing of ESS and/or reversible substation should be feasible. In addition, it introduces insight into the parameters impacting recuperating regenerative energy and consequently into the economic and environmental benefits.

\section{REFERENCES}

[1] M. Chymera, A. C. Renfrew, M. Barnes, and J. Holden, "Simplified Power Converter for Integrated Traction Energy Storage", IEEE Transactions on Transportation Electrification, vol. 60, no. 4, May 2011.

[2] Y. Iino, H. Hayashiya, M. Hino, S. Abe, K. Nakao, and K. Kudo, "Evaluation of installation effect of the energy storage system in d.c. traction power supply system", IEEE International Power Electronics and Motion Control Conference (PEMC), pp. 280-285, 2016.

[3] F. Foiadelli, M. Roscia, and D. Zaninelli, "Optimization of Storage Devices for Regenerative Braking Energy in Subway Systems", IEEE Power Engineering Society General Meeting, pp. 6, 2006.

[4] Z. Tian, S. Hillmansen, C. Roberts, P. Weston, N. Zhao, L. Chen, et al., "Energy evaluation of the power network of a DC railway system with regenerating trains," IET Electrical Systems in Transportation, in press. DOI: http://dx.doi.org/10.1049/iet-est.2015.0025.

[5] S. Lu, P. Weston, S. Hilmansen, H. B. Gooi, C. Roberts, "Increasing the Regenerative Braking Energy for Railway Vehicles", IEEE Transactions on Intelligent Transportation Systems, Dec. 2014.

[6] P. H. Henning, H. D. Fuchs, A. D. Le Roux, and H. du T. Mouton, "A 1.5MW seven-cell series-stacked converter as an active power filter and regeneration converter for a dc traction substation," IEEE Trans. Power Electron., vol. 23, no. 5, pp. 2230-2236, Sep. 2008

[7] P. J. Grbovic, P. Delarue, P. Le Moigne, P. Bartholomeus, "Modeling and Control of the Ultracapacitor-Based Regenerative Controlled Electric Drives", IEEE Transactions on Industrial Electronics, Aug. 2011.

[8] T. Kulworawanichpong, "Multi-train modeling and simulation integrated with traction power supply solver using simplified Newton-Raphson method", Journal of Modern Transportation, Dec 2015.

[9] R. Barrero, O. Hegazy, P. Lataire, T. Coosemans, J. Van Mierlo, "An Accurate Multi-Train Simulation Tool for Energy Recovery Evaluation in DC Rail Networks", International Review on Modelling \& Simulations; Dec 2011, Vol. 4 Issue 6, p2985.

[10] C. J. Goodman, "Overview of electric railway systems and the calculation of train performance," in Proc. IET Prof. Develop. Course Elect. Traction Syst., Nov. 2008, pp. 1-24.

[11] D. Crolla, B. Mashadi, "Vehicle powertrain concepts" in Vehicle powertrain systems: integration and optimization, Wiley, Jan. 2012, ch. 1.

[12] X. Li, X. Xu, "Application of improved Adaptive Genetic Algorithm in Train Energy Saving" in Proceedings of the Fourth International Forum on Decision Sciences, Springer Singapore, 2017, ch. 2, sec. 2.2, pp. 724730.

[13] K. Ogura, K. Nishimura, T. Matsumura, C. Tonda, E. Yoshiyama, M. Andriani, W. Francis, R. Schmitt, A. Visgotis, and N. Gianfrancesco,"Test results of a high capacity wayside energy storage system using Ni-MH batteries for DC electric railway at New York City Transit," in Proc. Green Technologies Conf. (IEEE-Green), IEEE, 2011.

[14] L. Romo, D. Turner, and L. S. B. Ng, "Cutting traction power costs with wayside energy storage systems in rail transit systems," in Proc. ASME/IEEE Joint Rail Conf., 2005, pp. 187-192.

[15] S. Sagareli and V. Gelman, "Implementation of new technologies in traction power systems," in Proc. Asme/IEEE Joint Rail Conf., New York, 2004, pp. 141-146.

[16] M. Saleh, "DC traction system, Electrical train model - File Exchange MATLAB Central", Mathworks.com, 2017. [Online]. Available: https://www.mathworks.com/matlabcentral/fileexchange/63889-dctraction-system--electrical-train-model. [Accessed: 26- Jul- 2017]. 